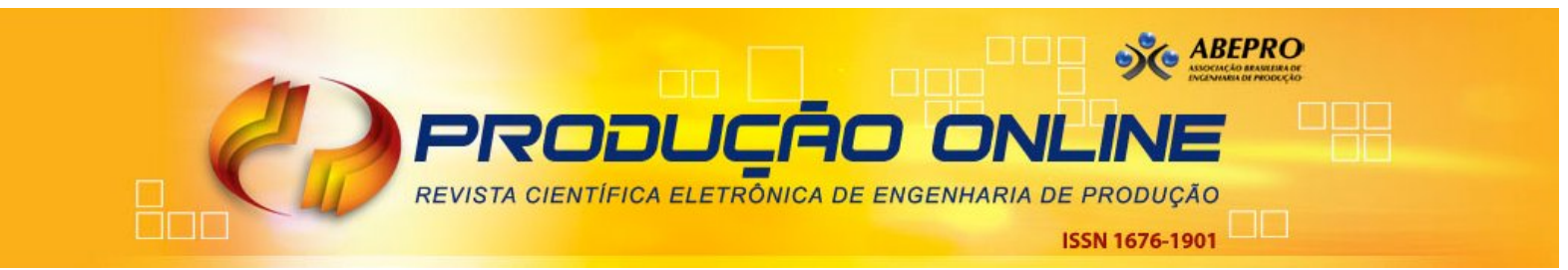

\title{
GESTÃO DE PROCESSOS NO SETOR PÚBLICO: UM ESTUDO NA UNIVERSIDADE FEDERAL DO TOCANTINS
}

\section{MANAGEMENT OF PROCESSES IN THE PUBLIC SECTOR: A STUDY AT THE FEDERAL UNIVERSITY OF TOCANTINS}

\author{
Jordana Teixeira de Melo Dias* E-mail: jordanamelo492@hotmail.com \\ Helga Midori Iwamoto* E-mail: helga.iwamoto@gmail.com \\ *Universidade Federal do Tocantins (UFT), Palmas, TO
}

\begin{abstract}
Resumo: Embora haja poucos relatos na literatura, nos últimos anos o foco em melhorias de processos vem se popularizando no setor público, e isto inclui o ambiente de ensino superior. É possível que as universidades debatam, com base em princípios e conceitos de qualidade, sobre as perspectivas de aprimorar seus processos. Nesse sentido, o objetivo deste artigo é avaliar em que medida as iniciativas de gerenciamento de processos da Universidade Federal do Tocantins (UFT), por meio dos fundamentos do Business Process Management (BPM) precisam ser melhoradas a partir da análise de 2 (dois) critérios (Pessoas e Processos) do Instrumento de Autoavaliação da Gestão do Extinto GesPública na percepção de gestores. Na fase de coleta de dados foi aplicada uma entrevista semiestruturada. Para a apreciação das informações foi realizada análise de conteúdo com triangulação de dados a fim de compreender os significados das falas dos gestores. Os resultados mostram que estes na atual estrutura administrativa estão à procura de melhorias nos processos que competem à sua gestão. No entanto, será um grande desafio para os gestores da UFT fortalecer os pontos positivos, bem como ajustar as dificuldades, os pontos negativos, que podem impedir as etapas do BPM se realizarem com sucesso.
\end{abstract}

Palavras-chave: Processos. Gestão de Processos. Setor Público. GesPública. Universidade.

\begin{abstract}
Although there are few reports in the literature, in recent years the focus on process improvements has become popular in the public sector, and this includes the higher education environment. It is possible that universities debate, based on principles and quality concepts, on the prospects of improving their processes. In this sense, the objective of this article is to evaluate to what extent the process management initiatives of the Federal University of Tocantins (UFT) through the fundamentals of Business Process Management (BPM) need to be improved by analyzing two (2) criteria (People and Processes) of the Self-Assessment Tool of the Management of the Extinct GesPública in the perception of managers. In the data collection phase, a semi-structured interview was applied. In order to evaluate the information, content analysis was performed with data triangulation to understand the meanings of the managers' speeches. The results show that these in the current administrative structure are looking for improvements in the processes that compete for their management. However, it will be a great challenge for UFT managers to strengthen the positive points, as well as to adjust the difficulties, negative points, that can prevent successful BPM steps.
\end{abstract}

Keywords: Processes. Processes management. Public sector. GesPública. University.

Revista Produção Online. Florianópolis, SC, v. 19, n. 1, p. 203-228, 2019. 


\section{INTRODUÇÃo}

Em função de poucos estudos na literatura acadêmica sobre melhorias em processos no ambiente público, surgiram necessidades de estabelecer práticas nas organizações públicas (BECKER; ALGERMISSEN; NIEHAVES; 2006), como o uso de ferramentas gerenciais da iniciativa privada, em especial o BPM. Esta abordagem foi criada para gerir e melhorar os processos organizacionais, tanto no setor privado quanto no setor público (NIEHAVES, 2010). Leva-se em consideração que o uso de técnicas e ferramentas do setor privado para o setor público, requer adaptação destas (ŠTEMBERGER; KOVACIC; JAKLIČ, 2007).

A abordagem de gestão por processos, no âmbito do setor público, ganhou espaço com a criação de programas de prêmios de qualidade. No Brasil, por volta da década de 1990, houve a introdução do conceito de qualidade total e reengenharia, fundamentandose nos critérios do Prêmio Fundação Nacional da Qualidade. O último programa relacionado foi o Programa Nacional de Gestão Pública e Desburocratização (GesPública) conhecido por ser uma política pública voltada para a modernização do Estado, com ênfase no cidadão.

Diante o exposto, o objetivo deste artigo é avaliar em que medida as iniciativas de gerenciamento de processos da Universidade Federal do Tocantins precisam ser melhoradas. Este exame foi possível a partir da análise de 2 (dois) critérios (Pessoas e Processos) do Instrumento de Autoavaliação da Gestão do Extinto GesPública pela percepção de gestores (Pró-Reitores e diretores).

Este estudo se justifica por contribuir com o rol de pesquisas sobre Gestão de Processos em Organizações Públicas, em particular em universidades públicas como a UFT que está inserida espacialmente em um território com riquezas naturais, variedade cultural e oportunidades, como o Tocantins. Complementando esta análise, o Relatório de Gestão do exercício de 2016 constata que:

[...] a Universidade Federal do Tocantins vem se estruturando para fortalecer a sua área do planejamento e gestão [...] valendo se de um modelo de planejamento que conta principalmente com o Planejamento Estratégico (PE)

Revista Produção Online. Florianópolis, SC, v. 19, n. 1, p. 203-228, 2019. 
/2014 - 2022 e o Plano de Desenvolvimento Institucional (PDI) / 2016 - 2020. Tais instrumentos contribuem para um melhor alcance da sua missão, visão de futuro, valores e objetivos estratégicos para o ensino superior do estado do Tocantins e do Brasil (UFT, 2017a, p. 8,)

Percebe-se que entender e compreender a atuação da UFT nessa temática da pesquisa poderá colaborar com o desenvolvimento regional em que esta inserida, no que tange a inovação e qualidade na gestão.

O trabalho está organizado em 5 seções, incluindo esta Introdução. O capítulo 2 apresenta uma revisão da literatura sobre a Gestão de Processos no Setor Público o qual serviu de base para tratarmos dos resultados da pesquisa empírica. O capítulo 3 apresenta a metodologia da pesquisa e traça o percurso metodológico proposto. O capítulo 4 apresenta e discute os resultados. Por fim, o capítulo 5 apresenta as conclusões e limitações da pesquisa. Na próxima seção é verificado como a literatura expõe os debates teóricos sobre a temática estudada.

\section{GESTÃO DE PROCESSOS NO SETOR PÚBLICO: BREVES DEBATES TEÓRICOS SOBRE PROCESSOS, PESSOAS E MELHORIA DA QUALIDADE NOS SERVIÇOS PÚBLICOS}

Apesar da popularização da Gestão de Processos no setor público nos últimos anos há poucos relatos na literatura sobre o tema (RADNOR; O'MAHONEY, 2013; MCADAM; DONAGHY, 1999; GULLEDGE JR; SOMMER, 2002; BIAZZI; MUSCAT; BIAZZI, 2011).

Ao longo dos anos tem havido uma transformação pela busca por desempenho nos resultados na administração pública da maioria dos países democráticos. Na mesma linha de raciocínio, Biazzi (2007, p. 16) complementa a sentença anterior quando diz: "[...] o setor público viu-se sob maior pressão para melhorar seu desempenho e demonstrar maior transparência e avaliação de resultados".

Tais necessidades de se aprimorar processos e melhoria de resultados na gestão em ambiente público surgiram de duas tendências: 1) a "onda" de reformas gerenciais 
(NOVA GESTÃo PÚBLICA) no setor público (início de 1980) e, 2) uma nova orientação das organizações públicas para os usuários clientes (orientação para o cliente) (ONGARO, 2004; WILLIAMS; SAUNDERS; STAUGHTON, 1999). Com relação ao mote, Ongaro (2004) considera que a orientação ao cliente (usuário final) pelas administrações públicas é vista como uma "legitimação" do setor público diante a sociedade.

Sabendo que as organizações sofrem pressões por mudanças conforme seu ambiente de atuação (FILHO; VILHENA; NASCIMENTO, 2014) percebe-se ao longo dos anos, que a administração pública tem sido confrontada com muitas exigências (BECKER; ALGERMISSEN; NIEHAVES, 2006), principalmente relacionadas às novas tecnologias que possam proporcionar serviços públicos de qualidade. Contudo, apesar da melhoria dos processos se nortearem pela utilização de tecnologias, o elemento humano é quem o realiza em todas as atividades para atender às diversas demandas que sobrevêm sobre esse fato (FALCÃO JÚNIOR, 2016). Desse modo, são as pessoas, capacitadas e motivadas, que executam processos e contribuem com os resultados propostos de uma organização (BRASIL, 2009a).

Sendo uma organização, pública ou privada, estas devem possuir um conjunto de processos inter-relacionados com a finalidade de alcançar seus objetivos e metas institucionais. Destarte, um processo possui uma ordem específica das atividades de trabalho considerando o tempo e o espaço, como um início e um fim, bem como inputs e outputs visivelmente identificados, a fim de produzir um resultado específico para um cliente ou mercado particular (DAVENPORT, 1994).

A literatura identifica 3 (três) tipos de processos organizacionais: gerenciais, finalísticos e administrativos. Apesar dos processos terem características específicas, os três tipos relacionados possuem aspectos em comum, como: envolver o encadeamento de atividades conectadas e interdependentes (transformação de entradas em saídas); possuir início e fim; possuir clientes, estes internos ou externos à organização (BIAZZI; MUSCAT; BIAZZI, 2011).

Tais processos são efetivados de modo contínuo pelo pessoal que faz parte da sua força de trabalho. Desse modo, se os processos são gerenciados com êxito pelos 
membros da organização, podem contribuir para alcançar a estratégia da empresa e melhorar a gestão dos processos principais, que agregam valor ao cliente (SENTANIN; CÉSAR; JABBOUR, 2008).

Domingues, Xavier e Birochi (2015) defendem que o foco nas pessoas é um dos aspectos da gestão por processos mais importantes, pois retratam a essência dos processos. Os autores destacam ainda que as pessoas que realizam as atividades e implementam melhorias em processos precisam ser motivadas para a realização das suas atividades.

Por outro lado, Carvalho (2015, p. 98) alerta sobre a existência de obstáculos, ou fatores "dificultadores" que podem impedir uma implantação da gestão por processos nas organizações com sucesso, como: "cultura organizacional; falta da visão por processos; resistência às mudanças de ambiente interno; falta de apoio da alta administração; falta de comprometimento dos funcionários; infraestrutura precária; falta de capacitação para os funcionários etc.". Segundo a autora quando tais fatores são executados de maneira positiva são conhecidos como "fatores críticos de sucesso". Dentre tais fatores a falta de capacitação de funcionários pode ser um grande obstáculo para implementação de projetos de melhorias em processos.

Buh, Kovačič e Štemberger (2015, p.246, tradução nossa) concordam que colaboradores devem entender "os objetivos, o conteúdo, os papéis e responsabilidades da Gestão de Processos e serem informados sobre o seu progresso". Entende-se assim que a articulação das relações humanas com processos é importante para atribuir responsabilidades.

Com isso, a necessidade de se adotar abordagens mais flexíveis e estratégicas para organizações públicas induziu muitos pesquisadores a extrair práticas de gestão da literatura de negócios com o intuito de aplicá-las na administração pública (PATELI; PHILIPPIDOU, 2011). Considera-se neste sentido, a importância do uso de técnicas e ferramentas gerenciais da iniciativa privada adaptadas (ŠTEMBERGER; KOVACIC; JAKLIČ, 2007). Conforme os autores, a mudança de processos de negócios no ambiente 
público está relacionada principalmente à unificação dos processos de negócio, à automação de algumas atividades e à supressão de algumas desnecessárias.

Outro fato também importante é que as instituições desenvolvam e implementem estratégia a fim de haver uma melhoria da qualidade de forma contínua (HAMZA, HASSAN E ALHADIDY, 2010). Dentro do contexto, a abordagem de gestão por processos, no âmbito do setor público, ganhou espaço com a criação de programas de prêmios de qualidade. A exemplo do Brasil, por volta da década de 1990, houve a introdução do conceito de qualidade total e reengenharia, fundamentando-se nos critérios do Prêmio Fundação Nacional da Qualidade. O último programa foi o Programa Nacional de Gestão Pública e Desburocratização (GesPública).

Este foi estabelecido pelo Decreto $n^{0} 5.378$ (BRASIL, 2005), revogado pelo Decreto $n^{\circ} 9.094$ (BRASIL, 2017a) e tinha como objetivo contribuir para a melhoria da qualidade dos serviços públicos prestados aos cidadãos e o foco em resultados. O programa, orientado pelo Modelo de Excelência da Gestão Pública (MEGP), teve como embasamento os princípios constitucionais da Administração Pública (legalidade, impessoalidade, moralidade, publicidade e eficiência).

O MEGP se estrutura em 8 (oito) critérios: governança, estratégias e planos, cidadão-usuário, interesse público e cidadania, informação e conhecimento, pessoas, processos e resultados (Figura 1).

Tais critérios são compostos por itens de avaliação com distribuição de pontos que podem variar de 250, 500 ou 1000 no somatório dos itens pelo Instrumento de Autoavaliação da Gestão Pública (IAGP). Este além de determinar o estágio de maturidade da gestão é um sistema de avaliação que possibilita clarificar os pontos fortes e as oportunidades de melhoria (aspectos gerenciais menos desenvolvidos na gestão em relação ao modelo) e que devem ser objeto de ações de aprimoramento. 
Figura 1 - Representação gráfica do Modelo de Excelência em Gestão Pública

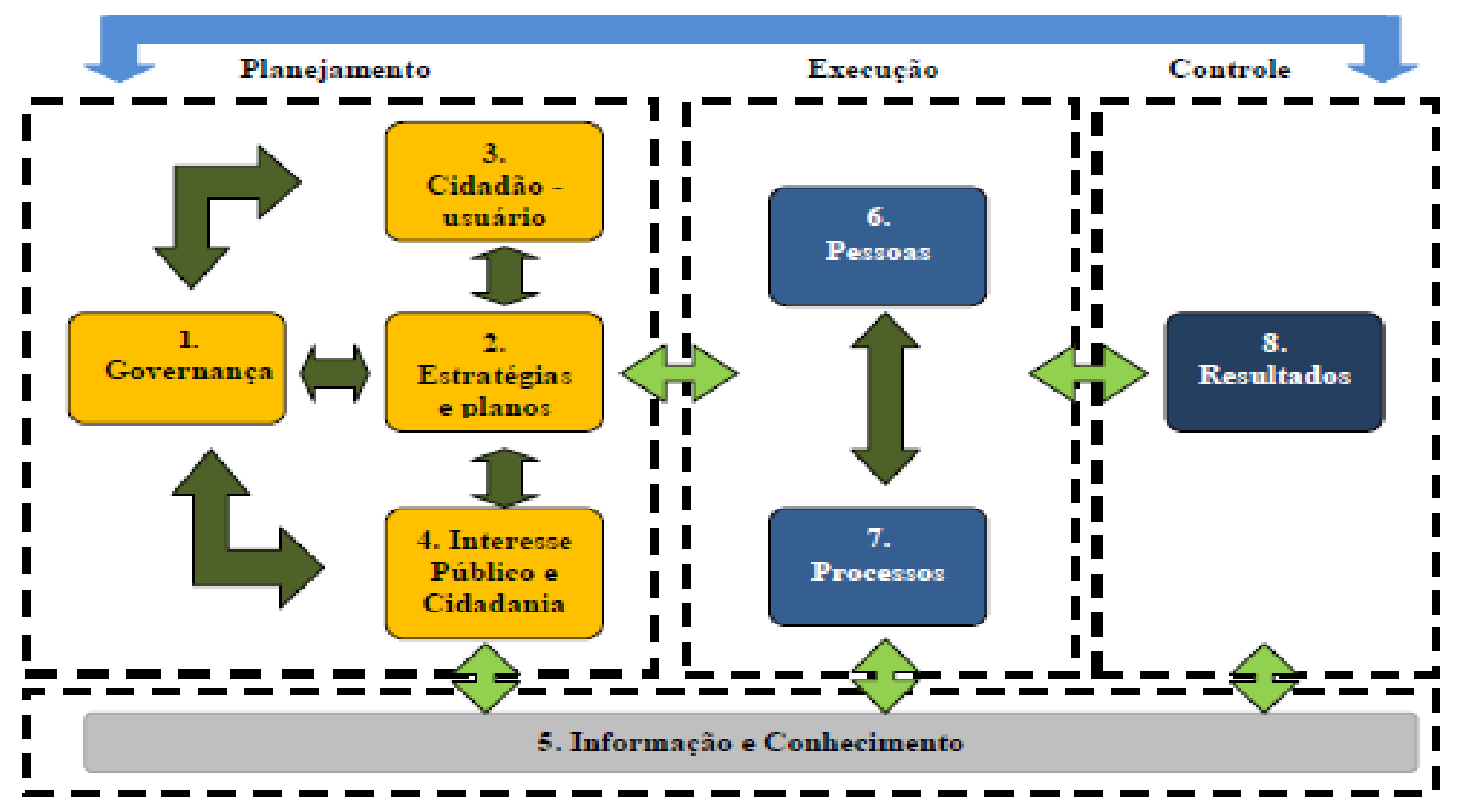

Avaliação

Fonte: Adaptado de Brasil (2016, p. 6)

A Figura 1 evidencia a relação sistêmica que existe entre os critérios (setas maiores) e entre as partes do modelo (setas menores) que juntos representam os 8 (oito) critérios do Modelo de Excelência em Gestão Pública. Estes critérios fazem parte de uma sistemática de avaliação da gestão, tomando-se como referência o estado da arte em gestão, cujo método foi desenvolvido a partir dos prêmios nacionais da gestão (Brasil, 2009a). Neste trabalho será analisado os 2 (dois) critérios Pessoas e Processos que faz parte da execução de um planejamento organizacional.

Ainda que não tivesse uma obrigatoriedade legal, o GesPública deixou como contribuição para as organizações públicas algumas ferramentas e fundamentos como a orientação por processos e informações. Destarte, o programa forneceu tecnologias de gestão a fim de instigar e promover a melhoria continuada de processos gerenciais e de resultados aos órgãos e entidades públicas que delas se apropriavam e que ainda podem Revista Produção Online. Florianópolis, SC, v. 19, n. 1, p. 203-228, 2019. 
ser utilizadas, a saber: Guia de Gestão de Processos do Governo; Simplificação Administrativa - Guia "D"; Carta de Serviços ao Usuário; Indicadores de Gestão e o IAGP.

Em ambiente universitário é possível que as universidades, em particular as públicas, realizem debates com base em princípios e conceitos de qualidade, sobre as perspectivas de aperfeiçoar seus processos para que possam cumprir seu papel social de promotoras do conhecimento. Em particular, no ano de 2011, a Universidade Federal do Tocantins aderiu ao Programa GesPública, parceiro da Fundação para o Prêmio Nacional da Qualidade (FPNQ). A instituição contou com os seguintes produtos do GesPública: a Autoavaliação da Gestão, realizada em 2011por meio do IAGP e, a Carta de Serviços aos Usuários ainda em uso conforme obrigatoriedade legal.

A universidade pública brasileira, diante de suas diversas responsabilidades e frente ao atual contexto de mudanças e transformações sociais, pode ter, em termos gerenciais, um instrumento de fundamental importância: a gestão de processos. No caso em particular, na UFT, este pode ser um estímulo à busca pela qualidade e um contributo importante para o atendimento às demandas governamentais e da sociedade.

Entender como estão as práticas de Gestão de Processos por meio das contribuições do GesPública tende a trazer vantagens. Roczanski (2009, p. 4) afirma que:

A gestão dos processos das organizações pode contribuir de maneira significativa para a gestão estratégica e a melhoria contínua das mesmas. Desta forma, os processos de trabalho em instituições referem-se à essência e a caracterização da atuação da organização e estão diretamente relacionados aos seus objetivos estratégicos e à geração de produto/serviço para o cliente-usuário interno ou externo.

Como referenciado, nos últimos anos, o foco em processos vem se tornando cada vez mais popular no setor público em geral, inclui-se neste o ensino superior (MACINTOSH, 2003). Hamza, Hassan e Alhadidy (2010) confirmam que a gestão de processos é o modelo mais apropriado para implementar a qualidade em ambientes universitários.

No caso da Universidade Federal do Tocantins, as demandas para identificação de processos (mapeamento e modelagem) para fins de organização do trabalho em 2016 
surgiram por meio dos planos e relatórios institucionais da Universidade, como o Planejamento Estratégico (2014 a 2022), o Plano de Desenvolvimento Institucional (2016 a 2020) e as oportunidades de melhorias apontadas pelo Relatório do GesPública em 2011. O próximo capítulo mostra a metodologia adotada para se cumprir o propósito deste trabalho.

\section{METODOLOGIA}

Este capítulo descreve o percurso metodológico adotado para se atingir o objetivo deste artigo relacionado à avaliação de iniciativas de gerenciamento de processos da UFT que precisam ser melhoradas. Enfatiza-se que os resultados são recorte de um objetivo específico da Dissertação da autora mencionada neste artigo.

O lócus da pesquisa foi a Universidade Federal do Tocantins, Câmpus de Palmas, especificamente Reitoria. A amostra da pesquisa é formada por 5 (cinco) Pró-Reitorias, num total de 7 (sete), ao nível estratégico e tático ao selecionar 10 (dez) gestores, sendo 5 (cinco) pró-reitores e 5 (cinco) diretores.

A seleção das unidades gestoras ocorreu levando-se em consideração a experiência delas com a gestão administrativa e a proximidade com os processos gerenciais, administrativos e finalísticos, bem como pelas necessidades de práticas de gestão de processos nos setores. Desta forma, foram entrevistados ${ }^{1}$ os gestores que atuam nos seguintes setores: Pró-Reitoria de Graduação e Diretoria de Registros Acadêmicos; Pró-Reitoria de Pesquisa e Pós-Graduação e Diretoria de Pesquisa; PróReitoria de Extensão, Cultura e Assuntos Comunitários e Diretoria de Extensão; PróReitoria de Avaliação e Planejamento e Diretoria de Planejamento; Pró-Reitoria de Administração e Finanças e Diretoria de Compras e Materiais.

\footnotetext{
${ }^{1}$ Siglas que identificaram os entrevistados: E1PR-Entrevistado n`1 Pró-Reitor (a); E2DR - Entrevistado $\mathrm{n}^{\circ} 2$ Diretor (a), e assim sucessivamente. Foram mantidas nas transcrições das entrevistas orais as expressões coloquiais com o objetivo de manutenção da veracidade do que foi dito.
} 
Em termos de procedimentos técnicos esta pesquisa se define quanto à abordagem do problema em pesquisa qualitativa, pois responde a um "universo de significados" e de percepções pessoais (MINAYO, 2001, p. 14). Com relação aos objetivos é uma pesquisa descritiva pela descrição de fatos e fenômenos de uma realidade local, a UFT, por meio de declarações pessoais e outras informações pertinentes conforme Triviños (1987) ressalta neste sentido. Já quanto aos meios de investigação é uma pesquisa bibliográfica pela construção e compreensão do referencial teórico. A pesquisa se enquadra também como estudo de caso por ser uma estratégia metodológica que mostrou o que é realizado na prática, com o uso de técnicas de entrevistas aplicadas in loco. Nesse contexto, Yin (2001, p. 32) reforça que "o estudo de caso [...] investiga um fenômeno contemporâneo dentro de seu contexto da vida real, especialmente quando os limites entre o fenômeno e o contexto não estão claramente definidos".

Em relação à fase de coleta de dados foi aplicado um roteiro de entrevista semiestruturada para captar as falas e percepções de gestores da UFT baseado no IAGP (250 pontos) com foco específico nas alíneas que tratam sobre pessoas e processos entre outras questões relacionadas aos fundamentos do BPM. Segundo Godoy, Bandeira de Mello e Silva (2006), a entrevista do tipo semi-estruturada visa compreender os significados que os entrevistados relacionam às questões e situações referentes ao tema de interesse do estudo.

Neste artigo o intuito foi mostrar de forma focalizada a representatividade dos 2 (dois) critérios (Pessoas e Processos) que se referem a execução do planejamento de uma organização e, que se encontram dentro do Modelo de Excelência em Gestão Pública. No entanto, reconhece-se a importância da integração de todos os 8 (oito) critérios dentro do modelo.

Para o exame dos dados coletados, foi realizada a análise de conteúdo com base nas orientações de Bardin (1977). A autora afirma que esta é um conjunto de procedimentos sistemáticos para a descrição do conteúdo das mensagens. A finalidade deste tipo de análise é a inferência de conhecimentos relativos às condições de produção 
de dados, assim como a busca de sentidos de um documento, de uma fala atribuídos pelos sujeitos da pesquisa.

Considerou-se também uma triangulação dos dados, que segundo Creswell é uma estratégia para se confirmar resultados de pesquisas qualitativas (CRESWELL, 2007), com uso de diferentes fontes de evidências (YIN, 2001), sendo levantamento das entrevistas confrontadas com fundamentação teórica. O próximo capítulo apresenta e discute os resultados que favoreceu o alcance do objetivo deste artigo por meio do percurso metodológico da pesquisa proposto.

\section{APRESENTAÇÃO E DISCUSSÃO DOS RESULTADOS}

Apresentam-se neste capítulo os resultados da pesquisa com as discussões e análises provenientes das entrevistas semi-estruturadas com apoio do referencial teórico. O Quadro 2 mostra as 2 (duas) categorias e assuntos analisados.

Quadro 2- Categorias temáticas para análise na percepção dos gestores

\begin{tabular}{|c|c|}
\hline CRITÉRIOICATEGORIA & ASSUNTOS ANALISADOS NAS QUESTÕES \\
\hline $\begin{array}{c}6 \\
\text { Pessoas }\end{array}$ & $\begin{array}{l}\text { - Integração dos níveis gerenciais da universidade em relação ao fluxo } \\
\text { de informações; } \\
\text { - Alinhamento das necessidades dos funcionários com processos e } \\
\text { sistemas de trabalho no setor; } \\
\text { - Cultura organizacional diante de mudanças em processos de } \\
\text { trabalho. }\end{array}$ \\
\hline $\begin{array}{c}7 \\
\text { Processos }\end{array}$ & $\begin{array}{l}\text { - Conhecimento dos processos finalísticos, de apoio e gerenciais da } \\
\text { - MFT; } \\
\text { - Melhor divulgação de processos finalísticos e apoio; } \\
\text { - Articulação dos processos finalísticos e de apoio com a missão da UFT; } \\
\text { - Sugestões de melhorias em processos finalísticos e de apoio; } \\
\text { - O processo de elaboração e o processo de gerenciamento do } \\
\text { orçamento; } \\
\text { - Critérios para seleção de fornecedores de serviços; } \\
\text { - O controle de processos finalísticos a partir de gerentes de processos; } \\
\text { - Escritório de processos na UFT. }\end{array}$ \\
\hline
\end{tabular}

Fonte: Elaborado pela primeira autora a partir do IAGP 250 Pontos do GesPública e referencial teórico.

A análise dos temas do Quadro 2 ocorreu por meio de uma avaliação entre pontos positivos e negativos de cada categoria temática, conforme se segue:

Revista Produção Online. Florianópolis, SC, v. 19, n. 1, p. 203-228, 2019. 


\section{I - Categoria 6 - Pessoas}

Esta categoria retrata os resultados das opiniões dos gestores entrevistados sobre a integração dos níveis gerenciais da Universidade em relação ao fluxo de informações, ao alinhamento das necessidades dos funcionários com processos e sistemas de trabalho no setor e à cultura organizacional frente às mudanças em processos de trabalho.

Segundo Domingues, Xavier e Birochi (2015), as decisões gerenciais quando passam a ser internalizadas, compreendidas e decididas pela visão de processos, possibilitam maior eficiência e benefícios. Desta forma, o sucesso de uma instituição depende cada vez mais do conhecimento, das habilidades, da criatividade e da motivação de sua força de trabalho, o que foi reforçado na opinião dos gestores entrevistados.

O primeiro ponto positivo desta categoria pela opinião dos gestores é que a maioria destes disse que a integração entre os níveis gerenciais da Universidade, levando em consideração a tomada de decisão e fluxo de informações entre as outras unidades se dá por meio de reuniões de gestão periódicas, pelos debates de demandas nos Conselhos Superiores ou indiretamente por meio dos fluxos dos processos de trabalho. As frases seguintes exemplificam alguns dos dizeres:

Olha, dentro da alta administração, ocorre uma vez por semana reunião de gestão [...] promovida pela própria PROAP [...] onde se faz uma avaliação conjunta da necessidade e principalmente da divisão orçamentária que também estão incluídos os diretores, ou UGs, a unidade de gestão (E1PR, grifo nosso).

[...] a integração ocorre da seguinte forma, os servidores e estudantes fazem suas demandas ao seu superior hierárquico que vai debater isso nos conselhos superiores. [...] os conselhos são formados por pessoas representativas tanto da gestão quanto da comunidade acadêmica (E5PR, grifo nosso).

$\mathrm{Na}$ nossa parte acadêmica cada processo tem um fluxo específico e é diferenciado. Então cada processo [...] vai ter uma unidade que é ela que vai ter um momento de tomada de decisão. Então essa integração, ela acaba que tem que ocorrer não tem muita opção por que é necessária para o processo. Então acaba que todo mundo vai se adequar ao fluxo e ao processo. Por que é necessário para a tomada de decisão (E4DR, grifo nosso). 
Outro ponto positivo é com relação ao alinhamento das necessidades dos funcionários com processos e sistemas de trabalho. Os gestores entrevistados, mesmo que busquem uma melhor gestão dos seus processos, atividades e execução de ações estratégicas, procuram uma harmonia no ambiente de trabalho com seus servidores, favorecendo a formação e a capacitação destes de forma a viabilizar o trabalho. Neste sentido, E6DR diz que "A gente tenta verificar na própria formação do servidor [...] então isso teoricamente já estão todos bem alinhados ao que fazem, gostam; já fizeram vários cursos [...] vários cursos na sua área de atuação [...]". Outro entrevistado enfatiza "[...] as atividades são feitas com base nas capacidades e nas aptidões de cada servidor [...], a gente chama, conversa e mostra e pergunta se tá tudo bem e tenta viabilizar aquele trabalho ali [...]" (E5PR). Diante disso, Navaratnam e Harris (1995) advogam que as relações humanas atreladas aos processos são importantes por 2 (duas) razões: atribuir responsabilidades e estabelecer a cultura da organização.

Como ponto negativo tem-se o fator "resistência" diante uma cultura organizacional ao lidarem com as mudanças em processos de trabalho, este evento na opinião da metade dos gestores. E6DR evidência este fato quando diz: "[...] minha experiência também enquanto servidor da UFT anterior, sempre a mudança é recebida com receio. Ninguém quer sair do seu nicho de trabalho". As falas de outros gestores também ratificam tal colocação:

Eu acredito que a cultura da UFT é um pouco resistente a questões de mudança. Nós demoramos um tempo de resposta talvez um pouco maior do que seria esperado ou que seria o ideal. Então essas melhorias elas, como a gente tem uma resistência a mudanças a gente demora um tempo (E2DR, grifo nosso).

Temos resistências, temos as pessoas que estão abertas a estas mudanças, mas o que eu sinto de uma forma um pouquinho mais intensa é a falta da relação das atividades que são desenvolvidas nos setores com uma função que é da universidade [...] (E3PR, grifo nosso).

Tem-se que a implementação de gestão de processos, BPM, em uma organização tende a gerar resistências geralmente pelas transformações na rotina de trabalho dos colaboradores e de procedimentos organizacionais. 
Sabendo que a mudança de cultura é um dos fatores de sucesso em transformações organizacionais (MCADAM; MITCHELL, 1998; ŠTANGOVÁ; VÍGHOVÁ, 2014), a maneira como aquela é incorporada é um dos maiores fatores responsáveis para sua aceitação com geração de resultados (TEIXEIRA LAGIOIA et al., 2008). Nesse sentido, Duvell e Jordan (2003) afirmam que a cultura organizacional se refere a uma série de premissas, estereótipos e mitos.

Foi mostrado nesta categoria como é importante a integração entre os níveis estratégicos da UFT, estabelecer relações com as pessoas a fim de criar condições de melhoria da qualidade nas relações de trabalho. Isto pode estabelecer uma sincronia na realização humana e profissional. Na próxima categoria são abordados assuntos relacionados à categoria Processos, mostrando a percepção dos gestores diante da identificação, divulgação, de melhorias em processos, gerente e escritório de processos.

\section{II - Categoria 7 - Processos.}

Esta categoria se refere à opinião dos gestores entrevistados com relação à gestão, divulgação e melhoria dos processos finalísticos, de apoio e gerenciais, bem como o entendimento sobre gestores de processos e perspectiva de um escritório de processos na UFT. Conforme a literatura ter um entendimento sobre os processos e compartilhar o conhecimento entre a organização como um todo e, principalmente, entre gestores de níveis hierárquicos diferentes, é fator indispensável para o aumento do desempenho de uma organização, inclusive para a implementação do BPM.

Paulus e Riemann (2013) ressaltam que a identificação do processo de negócio permite conhecer por que os processos de negócios são essenciais para a organização no sentido de cumprir as necessidades dos clientes ou de outras partes interessadas referentes ao modelo de negócio e à estratégia de resultados.

Entre os pontos positivos encontrados, no primeiro desta categoria percebe-se que a maioria dos gestores conhece os processos finalísticos e de apoio da universidade, como se observa nos exemplos das falas a seguir. 
Eu conheço alguns processos finalísticos [...] dentro do setor aqui. Eu posso citar que foi mapeado o do sistema de planejamento anual, foi mapeado o processo de construção do relatório de gestão, o processo de organização e distribuição do orçamento (E2DR).

Sim, a gente conhece talvez não conheça todos os mecanismos gerenciais, mas os processos finalísticos nossos estão basicamente relacionados com a qualidade dos cursos de pós-graduação, com a captação de recursos para pesquisa [...] com o sucesso de formatura de nossos estudantes, na obtenção dos graus de especialista, mestre, doutor e pós-doutor [...] (E5PR).

As frases citadas demonstram que uma das vantagens que a Universidade possui neste momento é ter divulgados muitos modelos de processos, organizados ainda por setor, devido ao seu caráter funcional e hierárquico. Pode-se dizer que, apesar da UFT ainda estar caminhando, olhando para os seus processos a fim de melhorias, está implantando, uma cultura de conhecimento, de modo a familiarizar as pessoas com a importância de seus processos de trabalho. E5DR neste contexto comenta: "Essas melhorias que foram realizadas, como por exemplo, a determinação dos fluxos e o esclarecimento de todas as etapas de cada unidade ter competências foi fundamental porque permite um melhor planejamento [...] todos os passos estão bem determinados" (E5PR).

O segundo ponto positivo considerado nesta pesquisa diante desta categoria foram as sugestões para a divulgação dos processos. Os gestores citaram investir em propaganda; tecnologia; comunicação; ter o processo como instrumento de decisão; haver mais comunicação; ter cerimônia de entrega dos diplomas de especialização; engajamento dos colegiados; haver melhoria no site da UFT; divulgar em mídias sociais.

Entre todas as sugestões supracitadas os fatores "comunicação" e "tecnologia" foram os mais comentados. Segundo um dos gestores entrevistados, para se melhorar a comunicação na Universidade, esta deveria estar mais aberta para a sociedade: "Nós ainda estamos muito fechados dentro da instituição" (E7PR). Neste sentido, a comunicação torna-se um dos elementos relevantes durante a implementação de um projeto de BPM e gestão de processos numa organização (MANFREDA; BUH; ŠTEMBERGER, 2015), por interferir nas relações organizacionais. Quanto à tecnologia, 
Gulledge Jr e Sommer (2002) ressaltam que estabelecer uma relação entre os processos organizacionais com novas tecnologias de informação é uma das razões para se implementar a gestão de processos na administração pública. A UFT neste quesito vem tentando melhorar cada vez mais, o que pode ser verificado no Relatório de Gestão de 2016, com apresentação dos resultados da gestão da informação da Universidade.

O terceiro ponto positivo quanto à articulação dos processos finalísticos e de apoio com a missão é que a maioria dos gestores confirma este fato ao se referirem ao PDI. E3PR comenta que "Eles estão articulados em termos do projeto da universidade, por exemplo, no Plano de Desenvolvimento Institucional e isso com certeza lá tem uma relação". Outro gestor também enfatiza "Como a universidade hoje toda praticamente ela trabalha em cima do PDI todas as ações que viram fluxos elas são do PDI Então tudo está articulado com a missão institucional" (E4DR). Outro relato diz:

Nós temos como base todo o trabalho da pró-reitoria planejamento feito com base no PDI. Esses processos eles foram pensados já conforme a gente já articulou dentro das diretrizes e dos eixos do planejamento que eles estão intimamente ligados com nossa missão (E2DR).

A literatura comenta que é relevante o alinhamento dos processos com a estratégia e a missão de uma instituição. Segundo Sentanin, César e Jabbour (2008), os processos de negócios de uma organização devem estar direta ou indiretamente articulados com o seu planejamento estratégico, caso contrário pode ocorrer um consumo de recursos capaz de desestruturar outros processos.

$\mathrm{O}$ quarto ponto positivo se refere às sugestões de melhorias em processos na opinião dos gestores entrevistados, conforme a Figura 2: 
Figura 2 - Sugestões de melhorias em processos finalísticos e de apoio na opinião dos gestores entrevistados

\section{Sugestões de melhorias em processos}

Realizar reuniões de gestão dos entes operadores

Levantar riscos dos processos; Levantar necessidades do usuário a partir do serviço

Incentivar processo formativo para o desenvolvimento de atividades

Padronizar os processos; Automatizar processos

Alocar mais recursos nos processos e atividades

Conscientizar os docentes com a missão

Melhorar os processos avaliativos das ações finalísticas; Aplicação de questionários para os usuários de serviços

Dar mais amplitude e visibilidade aos processos finalísticos e de apoio

Discutir a aplicação de recursos das ações da UFT

Aproximar a gestão superior das areas de apoio com discussão

Fonte: Elaborado pela autora a partir da pesquisa de campo

Observou-se pela Figura 2 que todos estes aspectos levantados pelos gestores são relevantes do ponto de vista do aperfeiçoamento dos resultados dos processos finalísticos e de apoio, a partir de melhorias a serem implementadas. Neste sentido, Biazzi, Muscat e Biazzi (2011) ressaltam que projetos de melhorias devem ser adaptados ao contexto do setor público pelo fato de existirem aspectos característicos desse ambiente como a cultura organizacional típica, questões políticas e burocracia. Deve-se levar em consideração, também, nas mudanças contínuas de processos de negócios no setor público, o foco no cliente (ŠTEMBERGER; KOVACIC; JAKLIČ, 2007). 
O quinto ponto positivo relacionado ao processo de elaboração e o processo de gerenciamento do orçamento mostra que os gestores são unânimes no fato de terem conhecimento de que os processos de elaboração e gerenciamento do orçamento levam em consideração o histórico e metas atingidas. E1PR neste sentido comenta "Até esse momento considera o histórico e a uma [...] distribuição atrelada ao mesmo critério da do MEC." E2DR, por sua vez, também diz "O processo de planejamento orçamentário leva em consideração o histórico do que já foi feito [...]". E8DR ainda comenta que "eles levam, até mesmo porque tem uma matriz orçamentária [...]". Outras falas na mesma linha de raciocínio ressaltam:

Ah sim, totalmente, pelo menos nesse período que a gente tem aqui toda reunião de gestão é apontado números anteriores [...] exemplo prático aqui [...] quantas bolsas tínhamos ano passado quantas a gente vai ofertar quanto a gente tem de verba para ele, quantas a gente atingiu [...] (E6DR).

[...] é possível dizer que ela leva em consideração sim o histórico nos últimos tempos [...] ficou mais difícil [...] devido à escassez de recursos [...] contingenciamento de recursos do governo federal." (E10DR).

Pelas falas acima é possível observar que os gestores têm conhecimento sobre o fato dos processos de elaboração e gerenciamento do orçamento considerarem o histórico e as metas atingidas. Contudo, uma realidade vista como fator capaz de mudar essa situação é a questão do contingenciamento de recursos vivenciado nos últimos anos. Verificou-se isso pelos discursos seguintes: "[...] nem sempre as nossas metas estratégicas são atendidas em função dos cortes [...]" (E3PR); "[...] ficou mais difícil levar em consideração o histórico devido à escassez de recursos, o contingenciamento de recursos do governo federal e a gestão tá tendo que tomar medidas contingenciais para poder atingir suas metas" (E10DR).

Em relação ao sexto ponto positivo todos os gestores reconhecem que para a seleção de fornecedores de serviços deve-se obedecer aos preceitos legais. Algumas verbalizações podem ser observadas para exemplificar estes resultados: "Isso não é tanto aqui na minha área, mas é considerado a princípio aquele que se atrela a exigência da licitação primeiro, aquele jurídico e depois de preço" (E1PR); "[...] Eu acredito assim 
que ligo para a gente fazer contratação de qualquer serviço nós fazemos um processo licitatório"(E2DR); "[...] a gente não tem muito a parte de fornecedores de serviços, mas creio que no ambiente a maioria é licitação [...]"(E3PR). Outra resposta se referiu à legislação: "[...] Lei 8.666 [...] a lei de licitações e compras no serviço público nós temos que obedecer este preceito [...]" (E9PR);

O sétimo ponto positivo mostra que os gestores sabem que os processos precisam ser gerenciados, eles têm essa consciência evidente nas falas. Neste sentido, a literatura fala que o gestor de processos é muito importante numa abordagem de BPM, sendo figuras essenciais, pois acompanham, dão suporte e gerenciam os processos organizacionais ponta a ponta, bem como lidam com mudanças necessárias nos departamentos envolvidos.

Maddern et al. (2014) ressaltam que os gestores devem sair de um nível gerencial funcional para um nível de gerenciamento de processos ponta a ponta a fim de realizar uma série de melhorias de desempenho bem como buscar a satisfação do cliente. $O$ verdadeiro papel de um proprietário, dono ou gerente do processo é ter a responsabilidade sobre operações de processo, ocupando uma posição relativamente alta na organização (BUH; KOVAČIČ; ŠTEMBERGER, 2015).

O oitavo ponto positivo abordado pelos entrevistados foi alguns se mostrarem receptivos a existência de um escritório de processos na UFT, ainda que numa minoria de 3 (três) gestores. Um desses gestores, E8DR, comenta "Eu acho que vai vir de grande valia acho que vai agregar, vai somar e a gente precisa melhorar os fluxos" (E8DR).

Entre os pontos negativos encontrados nesta categoria pelos resultados das entrevistas verificou-se que 4 (quatro) dos 10 (dez) gestores não se mostraram receptivos quanto à proposta de um escritório de processos, 3 (três)demonstraram não compreender bem suas funcionalidades. Entre os que não se mostraram receptivos os relatos foram "[...] eu acho que não seria o primordial [...] ter um escritório exclusivamente para isso eu acho que não tem necessidade. [...]" (E7PR). Outro gestor, E1PR, por sua vez diz: "Eu acho que não precisa acho que se cria muita identidade [...] Não realmente formalizada dessa forma [...]". E2DR também comenta: "[...] eu não sei exatamente se 
teria uma característica de escritório de processos [...] mas a universidade ela precisa estruturar e ela já começou os trabalhos". Por fim, E9PR relata: "Eu acho que é inviável por enquanto [...]" (E9PR).

Entre as justificativas declaradas quanto à resistência para a implantação de um escritório de processos na UFT alguns gestores ressaltam: "faz parte intrínseca da responsabilidade das atividades do Planejamento" (E1PR); "por questões de gratificação, quadro de servidores [...] formações de novas diretorias novos setores não tem tido muito êxito em função disso" (E9PR).

Diante da literatura acadêmica, o escritório de processos pode possibilitar a realização da gestão com abordagem em processos numa organização (DOMINGUES; XAVIER; BIROCHI, 2015). Neste sentido, o escritório de processos pode ser implantado em diversas formas de estruturas organizacionais e sua atuação irá depender da visão que a organização tem dos seus processos (CARVALHO, 2015; OLIVEIRA, 2014). Ademais, em um escritório de processos deve existir um gerente que responda à alta gestão, bem como um conjunto de procedimentos e regulamentações. Entretanto, há muitos fatores que podem influenciar a implementação de BPM relacionada à estruturação do escritório, como cultura, comunicação e patrocínio (OLIVEIRA, 2014).

Também como pontos negativos, estão uma minoria de gestores que não conhece o funcionamento de alguns processos de outros setores. E4DR neste caso diz: "Bom, na verdade eu creio que a gente conhece mais os processos que a gente trabalha. Então não temos muito conhecimento exceto a parte geral que envolve todas as próreitorias [...]". Outro entrevistado também comenta: "Sim, tenho conhecimento dos processos finalísticos na instituição de ensino no caso da Universidade - ensino, pesquisa e extensão -, mas não tenho muita propriedade para falar sobre o desenrolar de como se processa" (E10DR).

Outros pontos negativos se referem às falas de alguns gestores, 3 (três) no total: em relação a não possuírem informação suficiente sobre as principais competências e funções do gerente de processo, bem como de um Escritório de Processos numa organização que pretende implementar melhorias em processos a partir do BPM. 
Vimos nesta Categoria de Processos, na perspectiva de pontos positivos e negativos, as diversas percepções e opiniões dos entrevistados sobre os processos finalísticos, de apoio e gerenciais da UFT, sugestões para divulgação e melhorias de processos finalísticos e apoio, o conhecimento dos gestores quanto à articulação dos processos finalísticos e de apoio com a missão da UFT, comentários sobre o processo de elaboração e o processo de gerenciamento do orçamento, reconhecimento de critérios para seleção de fornecedores de serviços, a figura do gerente de processos e por fim, sobre o Escritório de processos na UFT.

No próximo capítulo são mostradas as considerações finais e limitações a partir dos resultados desta pesquisa.

\section{CONSIDERAÇÕES FINAIS}

O objetivo deste artigo foi avaliar em que medida as iniciativas de gerenciamento de processos da Universidade Federal do Tocantins (UFT) precisam ser melhoradas. Para tais fins, foram analisadas as percepções, opiniões, negativas e sugestões da alta direção, incluindo pró-reitores e diretores, com critérios (Pessoas e Processos) relacionados a processos do Instrumento de Autoavaliação do extinto GesPública. Incluem-se na análise de resultados os fundamentos do Business Process Management a fim de fornecer ferramentas para a realização do artigo, em especial numa instituição de educação do setor público.

A pesquisa permitiu uma compreensão de que iniciativas, práticas ou conhecimento de gerenciamento de processos pelos gestores são adequadas ou não, existentes ou não. Desta forma, os resultados evidenciados no estudo mostraram que os gestores na atual estrutura administrativa da UFT estão em busca de melhorias nos processos que competem a sua gestão.

Como limitações da pesquisa, sendo a UFT uma instituição com atividades complexas, ocorreram dúvidas por parte de alguns gestores quanto ao significado de 
algumas perguntas e mudança de foco em algumas respostas, não impedindo a realização do trabalho.

Percebe-se que as administrações públicas, caracterizadas ainda de forma burocrática, poderão encontrar muitas dificuldades na implementação da gestão de processos. Cabe à gestão da Universidade fortalecer os pontos positivos verificados nas percepções dos gestores e reparar os pontos negativos apontados nas falas, para que se realizem com sucesso as etapas de BPM na organização.

\section{REFERÊNCIAS}

BARDIN, L. Análise de conteúdo. Tradução Luís Antero Rego e Augusto Pinheiro. Lisboa: Edições 70, 2006.

BECKER, J.; ALGERMISSEN, L.; NIEHAVES, B. A procedure model for process oriented egovernment projects. Business Process Management Journal, v. 12, n. 1, p. 61-75, 2006. http://dx.doi.org/10.1590/S0104-530X2011000400013

BIAZZI, M. R. de. Instituições públicas de ensino superior: estudo de casos de aperfeiçoamento de processos administrativos. 2007. Dissertação (Mestrado). Universidade de São Paulo. Disponível em: http://www.teses.usp.br/teses/disponiveis/3/3136/tde-09082007181330/en.php. Acesso em: 30 jul. 2016.

BIAZZI, M. R.de; MUSCAT, A. R. N.; BIAZZI, J. L. de. Modelo de aperfeiçoamento de processos em instituições públicas de ensino superior. Gest. Prod., São Carlos, v. 18, n. 4, p. 869-880, 2011. http://dx.doi.org/10.1590/S0104-530X2011000400013

BUH, B.; KOVAČIČ, A.; ŠTEMBERGER, M. I. Critical success factors for different stages of business process management adoption-a case study. Economic Research-Ekonomska Istraživanja, v. 28, n. 1, p. 243-258, 2015.

https://doi.org/10.1080/1331677X.2015.1041776

BRASIL. Decreto no 5.378 de 23 de fevereiro de 2005. Institui o Programa Nacional da Gestão Pública e Desburocratização - GESPÚBLICA. Diário Oficial [da] República Federativa do Brasil, Brasília, DF, 24 fev. 2005. p. 2.

Disponível em:

http://pesquisa.in.gov.br/imprensa/jsp/visualiza/index.jsp?jornal=1\&pagina=2\&data=24/02/2005. Acesso em: 15 maio 2016.

. Ministério do Planejamento, Orçamento e Gestão. Secretaria de Gestão. Programa Nacional de Gestão Pública e Desburocratização - GesPública; Prêmio Nacional da Gestão Pública - PQGF; Documento de Referência; Fórum Nacional 2008/2009. Ministério do Revista Produção Online. Florianópolis, SC, v. 19, n. 1, p. 203-228, 2019. 
Planejamento, Orçamento e Gestão, Subsecretaria de Planejamento, Orçamento e Gestão. Brasília: MP, SEGES, 2009a. Disponível em: $\leq$ http://www.planejamento.gov.br/secretarias/upload/Arquivos/segep/eventos/2013/documento referencia2009 29abr.pdf/view>. Acesso em: 18 mai. 2016.

. Ministério do Planejamento, Orçamento e Gestão. Secretaria de Gestão Pública. Programa GESPÚBL ICA, Instrumento par a Avaliação da Gestão Pública - 250 Pontos. Brasília; MP, SEGEP, 2015. Versão 1/2016. Disponível em: http://www.gespublica.gov.br/sites/default/files/documentos/gagp-250 pontos novo.pdf. Acesso em: 12 mar. 2017.

Decreto $n^{\circ}$ 9.094, de 17 de julho de 2017. Dispõe sobre a simplificação do atendimento prestado aos usuários dos serviços públicos, ratifica a dispensa do reconhecimento de firma e da autenticação em documentos produzidos no País e institui a Carta de Serviços ao Usuário. Diário Oficial [da] República Federativa do Brasil, Brasília, DF, 18 jul. 2017. p. 2. 2017a. Disponível em:

http://pesquisa.in.gov.br/imprensa/jsp/visualiza/index.jsp?jornal=1\&pagina=2\&data=18/07/2017. Acesso em: 18 jul. 2017.

CARVALHO, K. A.de. Gestão por processos organizacionais na Universidade de Brasília: estudo de caso - Dissertação (Mestrado) - Universidade de Brasília - DF, 2015.

Disponível em: <http://repositorio.unb.br/handle/10482/19446>. Acesso em: 09 abr. 2016.

CRESWELL, J. W. Projeto de pesquisa métodos qualitativo, quantitativo e misto. Projeto de pesquisa métodos qualitativo, quantitativo e misto. Tradução Luciana de Oliveira da Rocha. 2. ed. Porto Alegre: Artmed, 2007.

DAVENPORT, T.H. Reengenharia de processos: como inovar na empresa através da tecnologia da informação. Rio de Janeiro: Campus, 1994.

DOMINGUES, F. de M. F.V.; XAVIER, W. G.; BIROCHI, Renê. Gestão por processos: uma análise da ferramenta de gestão utilizada no poder judiciário de Santa Catarina. Revista Eletrônica de Estratégia \& Negócios, v. 8, n. 1, p. 199-238, 2015.

http://dx.doi.org/10.19177/reen.v8e12015199-238

DUVELL, F.; JORDAN, B. Immigration control and the management of economic migration in the United Kingdom: organizational culture, implementation, enforcement and identity processes in public services. Journal of Ethnic and Migration Studies, v. 29, n. 2, p. 299-336, 2003. https://doi.org/10.1080/1369183032000079620

FALCÃO JÚNIOR, Marcos Antônio Gomes; SANTOS, Raimundo Nonato Macedo dos. A gestão de processos na análise das atividades de seleções públicas simplificadas: estudo de caso em uma prefeitura. Navus - Revista de Gestão e Tecnologia, [S.I.], v. 6, n. 2, p. 06-19, apr. 2016. https://doi.org/10.22279/navus.2016.v6n2.p06-19.324

FILHO, M. C. F.; VILHENA, M. das G.; NASCIMENTO, D. M. Gestão de processo na implantação de um Sistema de Informação Acadêmica: a experiência da UFPA. Revista Gestão Universitária na América Latina - GUAL, v. 7, n. 2, p. 69-85, 2014.

Revista Produção Online. Florianópolis, SC, v. 19, n. 1, p. 203-228, 2019. 
http://dx.doi.org/10.5007/1983-4535.2014v7n2p69

GODOY, C. K; BANDEIRA DE MELLO, R. B. de; SILVA, A. B. da. Pesquisa qualitativa em estudos organizacionais, estratégias e métodos. São Paulo: Saraiva, 2006.

GULLEDGE JR, T. R.; SOMMER, R. A. Business process management: public sector implications. Business Process Management Journal, v. 8, n. 4, p. 364-376, 2002. http://dx.doi.org/10.1108/14637150210435017

HAMZA, T. T.; HASSAN, A.; ALHADIDY, M. A. Developing a Service Oriented Process Management System for University Quality Assurance. International Journal of Engineering Science and Technology, v. 1, n. 2, p. 7-17, 2010.

JURISCH, M. C.; IKAS, C.; WOLF, P.; KRCMAR, H. Key Differences of Private and Public Sector Business Process Change. e-Service Journal, v. 9, n. 1, p. 3-27, 2013.

https://doi.org/10.2979/eservicej.9.1.3

MACINTOSH, R. BPR: alive and well in the public sector. International Journal of Operations \& Production Management, v. 23, n. 3, p. 327-344, 2003.

https://doi.org/10.1108/01443570310462794

MADDERN, H.; SMART, P. A.; MAULL, R. S.; CHILDE, S. End-to-end process management: implications for theory and practice. Production Planning \& Control, v. 25, n. 16, p. 13031321, 2014. https://doi.org/10.1080/09537287.2013.832821

MANFREDA, A.; BUH, B.; ŠTEMBERGER, M. I. Knowledge-intensive process management: a case study from the public sector. Baltic Journal of Management, v. 10, n. 4, p. 456-477, 2015. https://doi.org/10.1108/BJM-10-2014-0170

MCADAM, R.; DONAGHY, J. Business process re-engineering in the public sector: A study of staff perceptions and critical success factors. Business Process Management Journal, v. 5, $n$. 1, p. 33-52, 1999. https://doi.org/10.1108/14637159910249135

MCADAM, R.; MITCHELL, N. Development of a business process re-engineering model applicable to the public sector. Total Quality Management, v. 9, n. 4-5, p. 160-163, 1998. https://doi.org/10.1080/0954412988802

NAVARATNAM, K. K.; HARRIS, B. Quality process analysis: a technique for management in the public sector. International Journal of Public Sector Management, v. 8, n. 1, p. 11-19, 1995. https://doi.org/10.1108/09513559510077797

NIEHAVES, B. Open process innovation: The impact of personnel resource scarcity on the involvement of customers and consultants in public sector BPM. Business Process Management Journal, v. 16, n. 3, p. 377-393, 2010.

https://doi.org/10.1108/14637151011049412 
OLIVEIRA, J. Fatores envolvidos na estruturação de um Escritório de Processos em uma organização pública: uma pesquisa-ação. 2014. Dissertação (Mestrado) - Universidade Federal de Pernambuco. Ciência da Computação. Disponível em: http://repositorio.ufpe.br/handle/123456789/11553. Acesso em: 01 dez. 2017.

ONGARO, E. Process management in the public sector: the experience of one-stop shops in Italy. International Journal of Public Sector Management, v. 17, n. 1, p. 81-107, 2004. https://doi.org/10.1108/09513550410515592

PATELI, A.; PHILIPPIDOU, S. Applying business process change (BPC) to implement multiagency collaboration: the case of the Greek public administration. Journal of theoretical and applied electronic commerce research, v. 6, n. 1, p. 127-142, 2011.

https://doi.org/10.4067/S0718-18762011000100009

PAULUS, S.; RIEMANN, U. An approach for a business-driven cloud-compliance analysis covering public sector process improvement requirements. International Journal of Managing Public Sector Information and Communication Technologies, v. 4, n. 3, 2013. https://doi.org/10.5121/ijmpict.2013.4301

RADNOR, Z.; O'MAHONEY, J. The role of management consultancy in implementing operations management in the public sector. International Journal of Operations \& Production Management, v. 33, n. 11/12, p. 1555-1578, 2013. https://doi.org/10.1108//JOPM-07-2010-0202

ROCZANSKI, C. R. M. A Gestão de Processos em Ambientes Universitários: o exemplo da Unicamp. IX Colóquio Internacional sobre Gestão Universitária na América do Sul. 2009. Disponível em: https://repositorio.ufsc.br/handle/123456789/25885/browse?value=ROCZANSKI\%2C+CARLA+ REGINA+MAGAGNIN\&type=author. Acesso em: 09 abr.2016.

SENTANIN, O. F.; CÉSAR, F. A. S.; JABBOUR, C. J.C. Business process management in a Brazilian public research centre. Business Process Management Journal, v. 14, n. 4, p. 483496, 2008. https://doi.org/10.1108/14637150810888037

ŠTANGOVÁ, N.; VÍGHOVÁ, A. Process Management--New Way Of Selfgovernment Functioning. European Scientific Journal, v.1, p.141-151, 2014.

ŠTEMBERGER, M. I.; KOVACIC, A.; JAKLIČ, J. A methodology for increasing business process maturity in public sector. Interdisciplinary Journal of Information, Knowledge, and Management, v. 2,p. 119-133, 2007. https://doi.org/10.28945/3156

TEIXEIRA LAGIOIA, U. C.; RIBEIRO FILHO, J. F; FALK, J. A.; LIBONATI, J. J.; DE GUSMÃO LOPES, J. E. A gestão por processos gera melhoria de qualidade e redução de custos: o caso da unidade de ortopedia e traumatologia do hospital das clínicas da Universidade Federal de Pernambuco. Revista Contabilidade \& Finanças, v. 19, n. 48, p. 77-90, 2008 http://dx.doi.org/10.1590/S1519-70772008000300007 
TRIVIÑOS, A. N. S. Introdução à pesquisa em ciências sociais: a pesquisa qualitativa em educação. São Paulo: Atlas, 1987.

UFT. Relatório de gestão do exercício de 2016. Palmas, TO: UFT, 2017 a.

WILLIAMS, C. S.; SAUNDERS, M. N.; STAUGHTON, R. V.W. Understanding service quality in the new public sector: an exploration of relationships in the process of funding social housing. International Journal of Public Sector Management, v. 12, n. 4, p. 366-380, 1999. https://doi.org/10.1108/09513559910282858

YIN, R. K. Estudo de caso: planejamento e métodos. Tradução Daniel Grassi. 2.ed. Porto Alegre: Bookman, 2001.

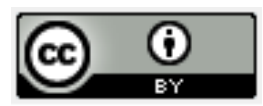

Artigo recebido em: 14/03/2018 e aceito para publicação em: 12/02/2019

DOI: http://dx.doi.org/10.14488/1676-1901.v19i1.3189 